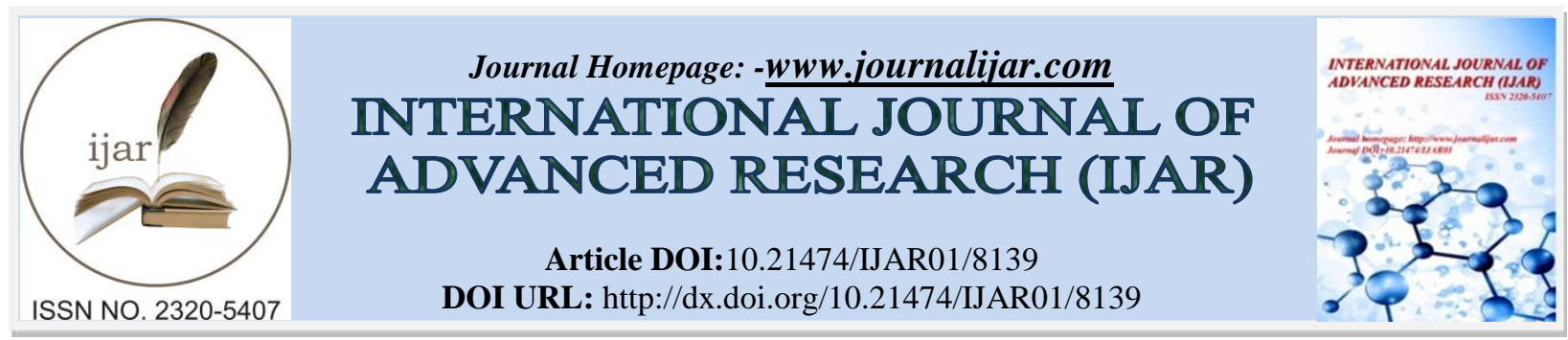

RESEARCH ARTICLE

\title{
RATE OF OCCURRENCE OF PHOTOSENSITIVITY IN SYSTEMIC LUPU ERYTHEMATOSUS.
}

\author{
Najah Abdul-Hameed ${ }^{1}$, Mustafa K. Al-Ezzi ${ }^{2}$ and Makram Al-Waiz ${ }^{3}$. \\ 1. Specialist Doctor in Rheumatology and Rehabilitation. Al-Yarmouk Teaching Hospital Baghdad/Iraq, \\ 2. Medicine Proff., College of Medicine, University of Baghdad. \\ 3. Dermatology Proff., College of Medicine, University of Baghdad.
}

\section{Manuscript Info}

Manuscript History

Received: 01 October 2018

Final Accepted: 03 November 2018

Published: December 2018

Keywords:-

Systemic Lupus Erythematosus, Joint pain, Skin rash.

\section{Abstract}

Background:Systemic Lupus Erythematosus is a chronic inflammatory disease appear to result from an immune-regulatory disturbance brought about by the interplay of genetic, hormonal and environmental factors. It is primarily a disease of young women. Its peak incidence occurs between the ages of 15 and 40 years.

Patients and methods:-Consecutive unselected patients with Systemic Lupus Erythematosus who met four or more of the American Rheumatism Association (1982) revised criteria for the classification of SLE, who were attending Baghdad Teaching Hospital both inpatients and out patients were included in the study. The time of the study was between Dec 1995 and May 1996. Examination of the patients was carried out at the rheumatology and dermatology units. A questionnaire was constructed for the purpose of the study.

Results: giving a ratio of female to male as 7:1. Mean age was 28.1 year for female and 26 years for male. In female the mean duration of the disease was 4.3 years and 2.2 years for male. Joint involvement was found in 56(87.5\%), renal disease in $37(57.8 \%)$, Central Nervous System disorder in 12 (18.7\%) Thirty-eight (59.3\%) had anemia, 22 (34.3\%) had leukopenia, 4(6.2\%) had thrombocytopenia, and 58 (90.6\%) had positive ANA. There was no significant difference in the prevalence of photosensitivity among different skin colour groups and in different disease activity groups of patients (P-vale: 0.97, 0.68 respectively).

Conclusion: Iraqi patients with SLE has high rate of photosensitivity. Sun protection is vital.

Copy Right, IJAR, 2018,. All rights reserved.

\section{Introduction:-}

Systemic Lupus Erythematosus (SLE) is a chronic inflammatory disease appear to result from an immune-regulatory disturbance brought about by the interplay of genetic, hormonal and environmental factors ${ }^{(\mathbf{1 , 2})}$.

It is primarily a disease of young women. Its peak incidence occurs between the ages of 15 and 40 years, with a female to male ratio of approximately $5: 1^{(3)}$.

The majority of patients with SLE demonstrate photosensitivity ${ }^{(4,5)}$, which constitutes one of the criteria of the American Rheumatism Association (ARA) for the diagnosis of SLE which further emphasizes its importance. Its 
defined as "skin rash as a result of unusual reaction to sunlight, by patients' history or physician observation" (6). In addition to the skin reaction patients may develop exacerbation of their systemic disease with sun exposure ${ }^{(4,5)}$.

The ultra violet UV portion of the electromagnetic spectrum lies between 200 and 400 no nm. Ultraviolet radiation is often arbitrarily divided into UV-A, UV-B and UV-C. The UV-A portion (320-400 nm) is not strongly absorbed by proteins and nucleic acids and does not cause erythema in normal skin at moderate doses in the absence of photosensitive chemicals. UV-B radiation $(290-320 \mathrm{~nm}$ ) is erythemogenic and present in the terrestrial solar spectrum. UV-C radiation $(200-290 \mathrm{~nm})$ (germicidal) is erythemogenic but doesn't reach the earth's surface ${ }^{(5,7,8)}$. One or more specific chromophores (light absorbing molecules) are involved in each photo biologic response. Photosensitive LE patterns react to UV-B and UV-C radiation and that a possible chromophore in this wavelength range is DNA. The chromophore responsible for UV-A photosensitivity is not known. The mechanism whereby photochemical reaction of the chromophore initiate clinical lesion is not understood ${ }^{(5)}$. Mechanisms leading to a single disease organ or to a systemic appearance of this disease entity are still not well understood ${ }^{(9)}$.

This study was designed to evaluate the rate of occurrence of photosensitivity in SLE (non-cutaneous disease) Iraqi patients.

\section{Patients and methods:-}

Consecutive unselected patients with SLE who met four or more of the ARA (1982) revised criteria for the classification of SLE, who were attending Baghdad Teaching Hospital both inpatients and out patients were included in the study. The time of the study was between Dec 1995 and May 1996. Examination of the patients was carried out at the rheumatology and dermatology units.

All patients were recruited to participate in the study after obtaining a verbal consent. A questionnaire was constructed for the purpose of the study. Information about sociodemographic variables: name, age, sex, occupation. Information about the disease were also collected: disease duration, medical history, drug therapy, appearance of photosensitive reactions in skin (exposed and unexposed areas) after exposure to sunlight, and whether accompanied by systemic manifestations such as fatigue, weakness, joint pain, fever, mouth ulcers, and hair fall.

Full clinical examination was performed with special attention for the following features: arthritis renal disease (>500 mg proteinuria/24 $\mathrm{hr}$. or $3+$ proteinuria or cellular casts), neuropsychiatric manifestations (seizures or psychosis), leucopenia, and thrombocytopenia.

The patients were allocated to one of three groups according to clinical assessment of disease activity ${ }^{(10)}$. The mild disease activity group: comprised those patients having mild signs and symptoms of the disease, clinical features in these patients included arthralgia, skin rash, mouth ulcers, alopecia, and general malaise. The intermediate group had evidence of moderate disease activity. The severe disease activity group had clinically obvious arthritis, nephritis, or neurologic disorder.

\section{Skin color of the patients was reported:-}

All patients with SLE were sent for complete blood count, erythrocyte sedimentation rate (ESR), antinuclear antibody testing (ANA), blood urea, serum creatinine, and general urine examination.

The lower limits of the following were: $\mathrm{Hb} 11.5 \mathrm{gm} / \mathrm{dI}$, WBC $4000 / \mathrm{mm}^{3}$, lymphocytes $1500 / \mathrm{mm}^{3}$, platelets $100.000 / \mathrm{mm}^{3}$, ESR upper limit $20 \mathrm{~mm} / \mathrm{hr}$.

\section{Statistical issue:-}

Statistical analysis of the results was done by Chi-square test, P-value less than 0.05 was considered significant.

\section{Results:-}

The study covered 64 patients with SLE. The age, sex, and disease duration of SLE patients were shown in tables-1. Female were 56(87.5\%)which was much higher than male $8(12.5 \%)$ giving a ratio of female to male as 7:1. Mean age was 28.1 year for female and 26 years for male. In female the mean duration of the disease was 4.3 years and 2.2 years for male. 
Table 1:-Mean Age and mean duration of the disease distributed according to sex

\begin{tabular}{|l|c|c|}
\hline \multirow{2}{*}{ Variable } & \multicolumn{2}{|c|}{ Sex } \\
\cline { 2 - 3 } & Female $(\mathrm{N}=56)$ & Male $(\mathrm{N}=8)$ \\
\hline Mean age & $28.1 \pm 8.34$ & $26 \pm 6.72$ \\
\hline Duration of disease & $4.3 \pm 2.35$ & $2.2 \pm 1.63$ \\
\hline
\end{tabular}

Joint involvement was found in 56(87.5\%), renal disease in 37 (57.8\%), Central Nervous System disorder in 12 (18.7\%) Thirty-eight (59.3\%) had anemia, 22 (34.3\%) had leukopenia, 4(6.2\%) had thrombocytopenia, and 58 (90.6\%) had positive ANA.

Table 2:-Different systems involved in disease activity in the study patients

\begin{tabular}{|l|c|c|}
\hline Disease & Number & Percent \\
\hline Joint involvement & 56 & 87.5 \\
\hline Renal disease & 37 & 57.8 \\
\hline CNS disorder & 12 & 18.7 \\
\hline Anemia & 38 & 59.3 \\
\hline leukopenia & 22 & 34.3 \\
\hline Thrombocytopenia & 4 & 6.2 \\
\hline Positive Antinuclear Antibody & 58 & 90.6 \\
\hline
\end{tabular}

Drugs used by patients with SLE are shown in table-2. Nonsteroidal anti-inflammatory drugs were at the top of the list, followed by Steroids 53(82.8\%), and Methotrexate 3(4.6\%) came at the bottom of the list.

Table 3:-Drugs therapy used in treatment of SLE in the study patients

\begin{tabular}{|l|c|c|}
\hline Drug & Number & Percent \\
\hline Non-steroidal anti-inflammatory & 57 & 89 \\
\hline Steroid & 53 & 82.8 \\
\hline Antimalarial & 9 & 14 \\
\hline Azathioprine & 8 & 12.5 \\
\hline Methotrexate & 3 & 4.6 \\
\hline
\end{tabular}

Tables-4 showed the skin areas in which a rash developed or worsened after sun exposure. Face was the leading place of photosensitivity $32(94.1 \%)$, arms $21(61.7 \%)$, and finally $2(5.8 \%)$.

Table 4:-Skin area in which a rash developed or worsen on sun exposure

\begin{tabular}{|l|c|c|}
\hline Skin area & Number & Percent \\
\hline Face & 32 & 94.1 \\
\hline Arms & 21 & 61.7 \\
\hline Legs & 17 & 50 \\
\hline Neck & 8 & 23.5 \\
\hline Back & 2 & 5.8 \\
\hline
\end{tabular}

We had 4 patients with type I skin color (always burn, never tan), 6 patients with type II skin colour (always burn, sometimes tan) 54 patients with type III skin colour (always tan, sometimes burn), photosensitivity was present in $2(50 \%), 3(50 \%)$, and $29(53.7 \%)$ of them respectively. There is no significant difference in the prevalence of photosensitivity among different skin colour groups of patients $(\mathrm{P}=0.97)$.

Photosensitivity was reported in $20(55.5 \%)$ patients with severe disease activity and in $6(42.8 \%)$ patients with intermediate disease activity and in $8(57.1 \%)$ patients with mild disease activity. There is no significant difference in the prevalence of photosensitivity in different disease activity groups of patients $(\mathrm{P}=0.68)$. 
Table 5:-Distribution of photosensitivity according to type of skin coloure and degree of disease activity

\begin{tabular}{|c|c|c|c|c|}
\hline \multirow[t]{2}{*}{ Type of skin color } & \multicolumn{3}{|c|}{ Photosensitivity } & \multirow{2}{*}{$\begin{array}{c}\text { Chi-sq } \\
\text { test }\end{array}$} \\
\hline & $\begin{array}{c}\text { Yes } \\
\mathrm{N}(\%) \\
\end{array}$ & $\begin{array}{c}\mathrm{NO} \\
\mathrm{N}(\%) \\
\end{array}$ & $\begin{array}{l}\text { Total } \\
\mathrm{N}(\%) \\
\end{array}$ & \\
\hline Type I (always burn, never tan) & $2(50)$ & $2(50)$ & $4(100)$ & \multirow{3}{*}{$\begin{array}{c}0.05 \\
0.97 *\end{array}$} \\
\hline Type II (always burn, sometimes tan) & $3(50)$ & $3(50)$ & $6(100)$ & \\
\hline Type III (always tan, sometimes burn) & $29(53.7)$ & $25(46.3)$ & $54(100)$ & \\
\hline \multicolumn{5}{|l|}{ Disease activity } \\
\hline Mild activity & $8(57.1)$ & $6(42.9)$ & $14(100)$ & \multirow{3}{*}{$\begin{array}{l}0.768 \\
0.68 *\end{array}$} \\
\hline Intermediate activity & $6(42.8)$ & $8(57.2)$ & $14(100)$ & \\
\hline Severe activity & $20(55.5)$ & $16(44.5)$ & $36(100)$ & \\
\hline Total & 34 & 30 & $64(100)$ & \\
\hline
\end{tabular}

\section{Discussion:-}

A study conducted by Dubois have reported rate of photosensitivity as $32 \%$ of patients with SLE ${ }^{\text {(11) }}$. In comparison to Iraqi patients a study conducted by AI Raw and co-workers reported photosensitivity in $48 \%$ of SLE patients ${ }^{\text {(12) }}$.

In the current study we depended on a questionnaire which was answered by the patients Through the development of standardized tests methods it has become possible to reproduce cutaneous lesions in the UV A and UVB spectrum. These methods allow a better definition of photosensitivity than clinical history did ${ }^{(\mathbf{1 3})}$. Because of lack of facilities, we used the method described by Wysenbeek which did not require sophisticated techniques ${ }^{(14)}$.

We differentiated between cutaneous and systemic symptoms secondary to sun exposure. Patients with SLE described photosensitivity over the face, arms, legs. neck and back in descending order. Petzelbauer et al found highly significant correlation between severe sun sensitivity and the presence of high antinuclear antibody titers ${ }^{(\mathbf{1 5})}$. Mond and Rothfield also found a significant correlation. There was no significant association with other SLE criteria (16)

In conclusion Iraqi patients with SLE has high rate of photosensitivity. Sun protection is vital.

\section{References:-}

1. Alarcon-Segova D., (1984). The pathogenesis of immune dysregulation in systemic lupus erythematosus. J. Rheumatol. 11:588-590.

2. Nuki G., (1991), Disease of connective tissues, bones and joint. In: Edwards C., and Bouchier I., Davidson's Princibles and Practice of Medicine. $16^{\text {th }}$ ed. Hong Kong, Churchill Iivingstone. PP 761-810.

3. Pisetsky DS (1993). systemic lupus erythematosus. Epidemiology, pathology and pathogenesis. In: Schumacher HR., ed. Primer on the Rheumatic Diseases 10 ${ }^{\text {th }}$ edition Atlanta, Georgia: Arthritis foundation. PP: 100-105.

4. Gladman DD, Urowitz MB., (1993), Systemic lupus erythematosus: Clinical feature. In: Schumacher HR., ed. Primer on the Rheumatic Diseases 10 ${ }^{\text {th }}$ edition Atlanta, Georgia: Arthritis foundation. PP: 106-111.

5. Kochevar IE., (1985), Action spectrum and mechanisms of UV radiation-induced injury in lupus erythematosus. J. invest-dermatol. 85"140s-143s.

6. Tan EM, Cohen AS, Fries JF, Masi AT, McShane DJ, Rothfield NF, et al. (1982) The 1982 revised criteria for the classification of systemic lupus erythematosus. Arthritis Rheum. 25:1271-1277.

7. Epstein JH, Tuffanelli DL, Dubois EL. (1965). Light sensitivity and lupus erythematosus. Arch Dermatol. 91:483-485.

8. Baer RL, Harber LC, (1966). Photobiology of lupus erythematosus. Arch Dermatol. 92:124-128.

9. Kalden JR, Winkler TH, Herrmann M, Krapf E., (1991). Pathogenesis of SLE: immunopathology in man. Rheumatol Int, 11:95-100.

10. Edmond JP, Bruneau C, Hughes GRV. (1975). Assessment activity in SLE: Aclinical and serological study. Ann Rheum Dis. 34:543-544.

11. Dubois EI, (1974), Lupus erythematosus. $2^{\text {nd }}$ ed. Los Angeles: University of Southern California Press. $289-91$.

12. Al-Rawi Z, Al-Shaarbaf, Al-Raheem E, Khalifa SJ. (1983). Clinical features of early cases of systemic lupus erythematosus in Iraqi patients. Br.J. Rheum. 22:165-171. 
13. Kind P, Lehmann P, Plewing G. (1993). Phototesting in lupus erythematosus. J. Invest-Dermatol. 100(1):53s$57 \mathrm{~s}$.

14. Wysenbeek AJ, Block DA, Fries JF. (1989). Prevalence and expression of photosensitivity in systemic lupus erythematosus. Ann Rheum Dis. 48:461-463.

15. Petzelbauer P, Binder M, Nekolakis P, Ortel B, Honigsmann H. (1992). Severe sun sensitivity and the presence of antinuclear antibodies in patients with polymorphous light eruption-like lesion. J-Am-Accad-Dermatol. 26(1): 28-74.

16. Mond CD, Peterson MG, Rothfield NF. (1989). Correletion of anti-Ro antibody with photosensitivity rash in systemic lupus erythematosus patients. Arthritis Rheum. 32(2): 202-204. 